\title{
Adverse Oral Manifestations of Cardiovascular Drugs
}

\author{
Dr. Shantala Arunkumar ${ }^{1}$, Dr. Anupama N Kalappanavar ${ }^{2}$, \\ Dr. Rajeshwari G Annigeri ${ }^{3}$, Dr. Shakunthala G K ${ }^{4}$ \\ ${ }^{I}$ Asst Prof, Dept of Oral Medicine \& Radiology, SDM college of dental sciences \& $\quad$ hospital, Sattur, \\ Dharwad. Karnataka. \\ ${ }^{2}$ Professor, Dept of Oral Medicine \& Radiology, College of Dental sciences \& hospital, Davangere. Karnataka. \\ ${ }^{3}$ Professor \& HOD, Dept of Oral Medicine \& Radiology, College of Dental sciences \& hospital, Davangere. \\ Karnataka. \\ ${ }^{4}$ Senior Lecturer, Dept of Oral medicine \& Radiology, MAHE institute of dental sciences \& hospital, Mahe, \\ Puduchcheri, India.
}

\begin{abstract}
Objectives: The aim of the study was to determine the frequency and nature of oral manifestations secondary to use of cardiovascular drugs.

Methods: Six hundred and three patients attending the general medicine departments of Bapuji hospital and Chigeteri Government hospital, Davangere, were evaluated for oral signs and symptoms like oral dryness, alteration in the taste or burning sensation and they were clinically examined for the presence of any oral mucosal lesions such as lichenoid reactions, xerostomia, gingival enlargements, aphthous ulcers, angioedema etc. Data were statistically analyzed with chi-square tests.

Results: Oral symptoms were recorded in 382 [67.4\%] patients with xerostomia being the most common [25.5\%], followed by dysgeusia [17.7\%], combination of xerostomia with dysgeusia [12.4\%] and burning sensation [6\%]. Oral signs were noticed in 181 [39.7\%] patients with clinically detectable xerostomia [15.3\%] being the common, followed by gingival enlargement [9\%] and lichenoid reaction [4.5\%]. There were no statistically significant differences [ $p>0.05]$ was noticed between age, gender, cardiovascular risk factors and cardiac disease, whereas association between cardiovascular drugs and oral symptoms were statistically highly significant [p<0.01] and with the signs it was statistically significant [p=0.01]. Conclusions: The frequencies of oral manifestations in patients receiving cardiovascular drugs were $67.4 \%$ [symptoms] and 39.7\% [signs] respectively. There was a significant correlation of oral manifestations with group of cardiovascular drugs and also with the increasing number of drugs.
\end{abstract}

Key Words: Adverse drug reactions, cardiovascular drugs, dysgeusia, oral drug reactions, xerostomia.

\section{Introduction}

The mouth serves as "a mirror of health or disease, as a sentinel or early warning system, as an accessible model for the study of other tissues and organs, and as a potential source of pathology affecting other systems and organs." 1

Several systemic factors are known to contribute to oral diseases or conditions, and among those are the intake of drugs. An adverse drug reaction [ADR] is defined by the WHO as a response to a drug which is noxious and unintended, and which occurs at doses normally used in man for the prophylaxis, diagnosis, therapy of disease, or for the modification of physiological function. ${ }^{2}$

Although many of the ADRs are non-serious and disappear when the drug is discontinued or the dose is reduced, others are serious and last longer. Therefore, ADRs are amongst the leading causes of morbidity, mortality and rising hospital costs. The exact pathogenesis of oral adverse reactions related to intake of medications is not well-understood, and the prevalence is not known. They are, however, believed to be a relatively common phenomenon, although medication-induced oral reactions are often regarded by the health profession as trivial complaints. ${ }^{2}$

Studies have shown that the drugs which most commonly cause adverse drug events [ADEs] are analgesics, anti-infective agents, cardiovascular drugs, anticoagulants, sedatives and anti-neoplastic drugs. ${ }^{4}$ Since many are asymptomatic and therefore are believed to go unreported. As more drugs are marketed and the population includes an increasing number of elderly, the number of drug prescriptions is also expected to increase. Accordingly, it can be predicted that the occurrence of ADRs, including the oral drug reactions [ODRs], will continue to increase. ${ }^{2}$

ODRs affect the oral mucous membrane, saliva production, and taste. The pathogenesis of these reactions, especially the mucosal ones, is largely unknown and appears to involve complex interactions among the drugs in question. ${ }^{2}$ 
Cardiovascular drugs [CVDs] were defined as those used for the treatment of hypertension, ischemic heart disease, congestive heart failure and/or arrhythmias. ${ }^{3}$ As the cardiovascular diseases are the most common group of medical disorders that dentists encounter, and the number of drugs prescribed for managing these conditions is staggering. This justifiably raises concern and probable confusion regarding side effects and possible drug interactions with medications, the dentist may deem necessary for dental care. ${ }^{4}$

A great many CVDs have the potential to induce adverse reactions in the mouth in the form of xerostomia, lichenoid reactions, burning mouth sensation, loss of taste sensation, gingival hyperplasia and bleeding, as well as extra oral manifestations such as sialadenosis, ${ }^{5}$ adverse reactions cannot be cured but we can make an attempt to treat or formulate a necessary alterations to reduce morbidity caused by such oral manifestations, thereby helping the patient to enjoy his routine daily life.

According to the data available, till date not many studies have been conducted on oral drug reactions of cardiovascular drugs. So we made an effort to conduct a study on oral manifestations of drugs used for the treatment of one such common disease and such studies enable us to obtain information on the incidence and pattern of ODRs induced by cardiovascular drugs in the local population. Similar data evaluation needs to be followed by dissemination of the information to the healthcare professionals, which could help to improve the quality of patient care by ensuring safer use of drugs.

\section{Aims \& Objectives:}

The aim of this study was to determine the frequency and nature of oral manifestations secondary to use of cardiovascular drugs.

\section{Methodology:}

An observational, non-comparative, study was carried out to monitor oral drug reactions [ODRs] associated with cardiovascular drugs in a teaching health care hospitals.

The study population comprised of 603 patients visiting the outpatient departments of General Medicine, Bapuji Hospital and Chigeteri Government Hospital. Davangere, and also the patients hospitalized in wards \& post cardiac care units [CCUs] for their various cardiovascular diseases during the period from June to August 2011. Inclusion criteria were patients receiving treatment with cardiovascular drugs and associated risk factors such as diabetes or smoking. Patients with dementia or confusion, severe illness and patients who refused to participate in the study were excluded. Study procedure was explained to the patient and informed consent was obtained from all the patients.

The detailed history pertaining to cardiovascular disease and their drugs has been elicited from the patients, as well as from their inpatient case records and treatment charts. Detailed history of oral symptoms like oral dryness, alteration in the taste or burning sensation was taken. Complete clinical examination of oral cavity for the presence of any oral mucosal lesions like lichenoid reactions, xerostomia, gingival enlargements, aphthous ulcers, angioedema etc was done using sterilized mouth mirror and straight probe against the artificially illuminated light. However the study did not include any confirmatory investigations such as histopathologic examination of lesional tissue, hence all the diagnoses pertaining to visually detected oral disease must be considered to be probable rather than definitive.

Data were presented as means \pm SD for continuous variable and as frequencies and percentages for categorical variables. Categorical variables were compared using 2-sided continuity correction chi-squired tests. All the analysis was performed with SPSS software (version 17.0) and the statistical significance set at $p<0.05$.

\section{Results}

A total of 603 cardiovascular patients [351 males and 252 females] were evaluated with the age range of 15 to 85 years [mean age of $54.6 \pm 2.17$ ].

Frequencies and percentages of CVD risk factors, type of cardiovascular disease, drug history, oral symptoms and signs of all the patients along with the mean number of medications taken per subject with or without oral manifestations are detailed in table1\&2. The number and percentage of ODRs reported for each group of drug is shown in the table3.

The most common cardiovascular disease noted in our study was hypertension [71.3\%], followed by other diseases like coronary artery diseases [18.7\%], congestive heart failure [4.1\%], cardiac arrhythmias [3\%], valvular heart diseases [2.8\%] and congenital heart diseases [0.3\%]. Number of patients with associated risk factors such as smoking [9.1\%], diabetes mellitus [8.8\%] and few patients had both smoking and diabetes mellitus [1.5\%], shown in Fig.1

In the present study majority of the patients were on $\beta$-adrenergic blockers [BABS], calcium-channel blockers $[\mathrm{CCBs}]$ and combination of drugs of coronary disease medication.

In the present study, all the 603 patients, who were on medications for their cardiovascular problems, were questioned about their oral symptoms. Out of 603 patients, 221 patients had no symptoms and in 
remaining 382 patients following symptoms were noted. The most common symptom recorded was the xerostomia [25.5\%], followed by dysgeusia [17.7\%], burning sensation [6\%]. There was also a combination of symptoms reported by the patients such as xerostomia with dysgeusia [12.4\%], dysgeusia with burning sensation [3\%], xerostomia with burning sensation [1.2\%], and combination of all symptoms i,e. Xerostomia, dysgeusia with burning sensation [2.8\%] was noticed, shown in Fig.2

On clinical examination of 603 patients for the presence of any signs of oral drug reactions, 422 patients did not have any oral signs and only 181 patients had one or the other signs such as, xerostomia [92\%] was being the most common, followed by the gingival enlargement [9\%], least being the lichenoid reaction [4.5\%], and lichenoid with xerostomia was present in few patients $(1.2 \%)$. Along with these signs some patients manifested with some rare findings like bilateral parotid enlargements [2.3\%], pedal edema [Amlodepine induced, $(0.33 \%)$ ], oral petechiae [0.16\%], shown in Fig.3

\subsection{Co-relation of the oral manifestations with the number of medications:}

The mean number of medications taken by the patients with or without symptoms was $3.4 \pm 2.0$ and $3.22 \pm 1.2$ respectively. And also mean number of medication taken by the patients with or without signs was $2.90 \pm 1.76$ and $2.49 \pm 0.91$ respectively, shown in table 2 .

\subsection{Cardiovascular drugs and associated clinical symptoms:}

The overall correlation between patients on cardiovascular drugs and their oral symptoms were statistically highly significant $[\mathrm{p}<0.001]$, shown in table 3 .

In the present study, most frequent complaint by the patient was xerostomia, which was reported maximum in patients on combination of $\beta$-adrenergic blockers [BABs] with calcium-channel blockers [CCBs] accounting for $21.7 \%$, followed by other drugs like CCBs [19.1\%], coronary artery disease medications [12.5\%], BABs \& ACEI [11.8\%] and BABs \& diuretics [9.2\%]. Lesser frequency of xerostomia was also reported in patients on $\mathrm{BABs}[6.6 \%]$, and patient on medications for cardiovascular disease and diabetes mellitus [5.9\%], followed by CCBs with anti-anxiety drugs [2\%]. Remaining patients who were on other cardiovascular drugs had least frequency of xerostomia $[<2 \%]$.

The symptom of dysgeusia was maximum in patients who were on combination of drugs for coronary artery diseases [16.8\%], followed by other medications including BABs with CCBs [15.9\%], CCBs [13.1\%] and CHF medication [10.3\%]. And was also noted in patients on medications for diabetes with CVS disease [9.3\%], and it was also a common symptom of patients taking combination of CCBs, BABs with antianxiety drugs [8.4\%], and BABs with diuretics [3.7\%].

Burning sensation was more in patients, who were medicated for coronary artery disease [60\%], followed by combination of BABs with diuretics [20\%], and in patients on combination of antidiabetic with cardiovascular drugs [20\%].

The patients also complained of one or more symptoms, out of which most common being xerostomia with dysgeusia. Which was reported more in patients on combination of BABs with CCBs [20\%] followed by combination of cardiovascular and antidiabetic drugs [16\%], coronary disease medications [12\%]. And 9.3\% patients with symptoms were on CCBs and combination of BABs with diuretics, $8 \%$ of cases were taking CCBs with antianxiety drugs. Patients on combination of BABs with ACEI, BABs and CCBs with antianxiety drugs accounted for $5.3 \%$. Less than $4 \%$ of symptoms were noted in patients on various other cardiovascular drugs.

Combination of dysgeusia and burning sensation was common complaint in patients, who were on drugs for diabetes and cardiovascular disease and also in patients taking BABs with ACEI [25\%], followed by CCBs and combination of CCBs with BABS [12.5\%]. Remaining drug groups showed frequency symptoms of less than $7 \%$.

In the present study some patients also complained of xerostomia, dysgeusia and burning sensation simultaneously. $23.5 \%$ of symptoms were noted by patients who were taking medication for diabetes with cardiovascular disease and in patients with coronary disease medications. Next frequency of symptoms were noted by patients on drugs for CHF [17.6\%], the patients on BABs, CCBs along with anti-anxiety drugs [11.8\%], followed by patients on CCBs, BABS with ACIE and combination of cardiovascular drugs with antianxiety medications accounted for $5.9 \%$.

However, the combination of xerostomia with burning sensation was reported to be the least frequent type of symptom, complained by patients who were on single or combination of drugs for HTN, CHF and coronary artery diseases have shown equal frequency of $14.3 \%$ in all the drug groups.

\subsection{Cardiovascular drugs and associated clinical signs:}

The correlation between the cardiovascular drugs and clinical signs were statistically significant [p=0.01], shown in table 3 . 
In clinical signs, xerostomia was the commonly noticed finding, significantly more frequent in patients taking coronary disease medication [20.7\%], followed by combination of drugs for cardiovascular disease and diabetes [13\%], BABs with diuretics and CCBs [10.9\%], BABs with CCBs [9.8\%], drugs for CHF [8.7\%], BABs with ACEI [7.6\%], and other drug groups showed a frequency of less than $5 \%$.

The next common clinical finding noticed was gingival enlargement, especially seen in patients on CCBs [33.3\%], and patients on combination of BABs with CCBs [27.8\%] and medications for coronary diseases [20.4\%], CHF [7.4\%] and in patients on CCBs with diuretics [1.9\%], in other drug categories the frequency of gingival enlargement noted to be less than $2 \%$.

The lichenoid reaction was noticed in patients who were on combination of drugs such as BABs with CCBs and CCBs with BABs [18.5], CCBs with antianxiety drugs [18.5\%], BABs with diuretics and coronary disease medication [14.8\%], and patients on antidiabetic with cardiovascular drugs [3.7\%], in other drug groups the lichenoid lesions was found to be less than $2 \%$.

In some patients there was a simultaneous manifestation of two signs, such as lichenoid reaction and xerostomia, and it was seen in patients on combination of cardiovascular and antidiabetic drugs [33.3\%], and in other drug groups such as CCBs, BABs with CCBs, BABs with CCB and anti-anxiety drugs, equal frequency of $16.7 \%$ was noticed.

\section{Discussion}

In a study conducted to evaluate oral drug reactions secondary to use of cardiovascular drugs, we have noticed that majority of the patients had hypertension [71.3\%], which reflects the high frequency of this condition in studied population. Followed by a coronary artery disease [18.7\%], congestive heart failure [4.1\%], cardiac arrhythmias [3\%], valvular heart disease [2.5\%], the least common type of CVS noticed was congenital heart disease with the frequency of $0.3 \%$. In risk factors smoking [9.1\%] was noticed more than diabetes [8.8\%]. High incidence of hypertension of $71.3 \%$ in studied population, which is in consistent with the high prevalence of this condition in adults population in India and worlds population [Zachariah MG et al.,2003; Kerney PM et al,. 2005] $]^{6}$ and the occurrence of coronary artery diseases [18.7\%] is in accordance with the study population in India [Gupta, 2008, Indian census 2001].

Out of 603 patients 382 [63.3\%] patients were complained of one or more oral symptoms and on clinical examination $181[30 \%]$ patients had clinically detectable signs. In our study maximum number of drugs taken by patients with symptoms and signs were $3.4 \pm 2.0$ and $2.90 \pm 1.76$ respectively, however number of drugs taken to cause symptoms or signs was comparatively less than the previous studies (Habbab KM et al 2010) ${ }^{7}$

The most frequent oral complaint was xerostomia in 152 subjects [25.5\%], which is already known to be a likely oral adverse effect of many groups of drugs [Smith and Burter, 1994; Shinkai et al, 2006]. However, the presently observed frequency is far below compare to the $80.5 \%$ reported in some studies of patients taking other drug therapies [Smith and Burtner, 1994].

In the present study xerostomia was noticed in high percentage of patients who were on CCBs and combination of CCBs with other drugs such as BABs, and also in patients taking combination of BABs with diuretics or ACEIs drugs and patients on antianxiety drugs. And it was also a common complaint in patients taking medications for diabetes with cardiovascular disease and coronary artery disease. All these antihypertensive drugs are known to cause xerostomia, as reported in many studies [Vlasses et al.,Persson et al,1991;Charls F et al. 1995; Baum et al., 2000; Anthony T. Vernillo, 2003; Sreebny and Schwartz, 1997; Cruz M P et. al., 2008] $]^{2,8,9,10,11}$ while BABs and diuretics have been suggested to cause xerostomia [Persson et al, 1991; Treckfus, 1995; Atkinson et al.,198] $]^{2,12}$

Frequency of high percentage of xerostomia could be due to multiple drug therapy which either through direct or indirect effects on salivary gland leading to hypofunction and dehydration. The reduced salivary flow may be due to anticholinergics effect of drugs added to it some drugs also decrease the total protein content of whole saliva. Some authors also state that xerostomia is due to age related changes in the gland or may be due to associated risk factors like smoking and diabetes. ${ }^{2,9,10,13}$

The dysgeusia was the common complaint of patients taking CCBs alone or CCBs in combination with other drugs, and also in patients on anti-arrhythmic drugs, this reported adverse profile is in accordance with the other studies [Mott et al.,1993;Dougall and McLay,1996; Spielmean,1998;Nicholls et al., McGovern et al., 1983; Mott et al., 1993]. ${ }^{2}$ Dysgeusia is also noticed with high percentage in patients on multiple drugs for cardiovascular disease with diabetes, patients on coronary artery disease and CHF. This potential side effect may be secondary to reduced salivary flow or due to secretion of these drugs in the saliva leading to altered taste. This alteration in the taste also may be due to smell distortion or hyposmia. ${ }^{14}$ Aspirin, statins, diuretics are also know to cause alteration in taste perception. [Mott et al., 1993; Cruz M P et.al. 2008]. There is some evidence that medications alter taste by affecting trace metal ions, which interact with cell membrane pores. ${ }^{15}$ Drugs alter the taste by either by interfering with the chemical composition or flow saliva, or by affecting taste receptor function or signal transduction. ${ }^{12}$ 
The oral burning was associated with patients on antidiabetic and cardiovascular drugs and combination of drug for coronary artery disease especially patients taking ACEIs, the possible reason may be due to diabetes itself may lead to desiccation of the mucosa and leading burning sensation [Vlasses et al, 1982; Savino and Haushalter 11992]. Even chronic hypo salivation has debilitating effect on integrity of oral mucosa might lead to increased tendency for infection that in turn may cause burning sensation. ${ }^{2}$

In the present study patients were on BABs, CCBs and also on multiple drug therapy for coronary artery diseases, arrhythmias, diabetes and cardiovascular disease, manifested with lichenoid reaction. This is in accordance with the reported literature by Hawk, 1980; Lamey et al., 1990; Swale and Mc Geegor, 2001. ${ }^{2}$

In the present study many patients manifested with mild to moderate forms of generalized gingival enlargement. This clinical finding was commonly associated with patients on CCBs and also in patients on combination of CCBs with other cardiovascular drugs; this reported adverse drug reaction is consistent with other studies [Marshall and Bartold, 1998; Hallmon and Rossman 1999; Fottore et al..1991;Baume et al,.1988;Ellis et al,.]. As majority of patients in our study were on amlodepine this may be the reason for mild form of enlargement in these patients, this finding in our study is supported by some authors who have stated that amlodepine has less effect on gingiva compared to other drugs of the same group. ${ }^{2}$

In our study we have noticed some rare clinical signs such as parotid enlargements, pedal edema, and these findings are in accordance with the studies by authors Anusha Ganeshalingum et al 2007; Jain et al 1991. Oral petechiae and eccymosis noticed in one of our patient who was on antiplatelet drug this has been supported by a study conducted by authors [Marta Cruz-Pamplona et al 2011]. ${ }^{14}$

\section{Conclusion}

Drug induced oral manifestations are the common symptoms observed by oral physician, especially patients who are on polypharmacy. Patients with cardiovascular diseases are mostly on multiple drugs, so incidences of oral drug reactions by cardiovascular drugs are expected. A wide spectrum of drugs can give rise to numerous adverse oral manifestations and sometimes these reactions are mistaken for primary oral lesions and treated accordingly, this may lead to inappropriate management of the patient. The awareness of oral drug reactions to cardiovascular medications and detection of a suspected reaction enables dental professionals to refer the patient back to his physicians or cardiologist, who can then determine whether it is appropriate to prescribe an alternative therapy or to continue with the same treatment. Therefore oral clinician should take a careful drug history and always include drug as one of the cause for oral and perioral manifestations, so that he can render best possible treatment for his patients.

\section{References:}

[1]. Louis F. Rose, Brian mealey, Laura minsk, Walter cohen. Oral care for patients with cardiovascular disease and stroke. JADA 2002;133:37s-44s.(9)

[2]. Topel LA, Kragelund C, Reibel J, Nauntofte B, oral adverse Drug Reactions To cardiovascular drugs. Crit Rev Oral Biol Med 2004;15(1):28-46.(1).

[3]. Fahimi F, Baniasadi S and Amini S. Indian journal of pharmaceutical research 2008;7(3):223- 8.(4)

[4]. Daniel E. Becker. Cardiovascular Drugs: Implications for Dental Practice:Part2-Antihyperlipidemics and Antithrombotics. Anesth Prog 2008; 55:49-56.(6)

[5]. Pamlona MC et al. Dental considerations in patients with heart disease. J clin Exp Dent 2011;3(2):e97-105.(2)

[6]. MG Zachariah, KR Thankappan, SC Alex, PS Sarma, RS Vasan, Prevalence, correlates, awareness, treatment and control of hypertension in a middle aged urban adult population in Kerala. Indian heart journal 2003;55; 245-51

[7]. Habbab,Moles DR, Porter SR. Potential oral manifestations of cardiovascular drugs. Oral diseases. 2010;16;769-773

[8]. Terry D Rees. The diabetic dental patient. Dent Clin N Am 1994; 38(3):447-63(11)

[9]. Murrah V A. Diabetes mellitus and associated oral manifestations. J of Oral Pathol 1985: 14, 271-281(12)

[10]. Ship J A. Diabetes and oral health: An overview. J Am Dent Assoc 2003; 134; 4S-10S(13)

[11]. Cruz MP, Küstner EC, Vicente JA, Ferrero XM, Thio EB, López JL. Adverse side effects of statins in the oral cavity. Med Oral Pathol Oral Cir Bucal. 2008 Feb1;13(2):E98-101.(16).

[12]. Scully C. Adverse drug reactions. In the orofacial region. Crit Rev Oral Biol Med. 15(4):221-240 (2004)(22)

[13]. Murrah V A, Crosson J T, Sauk J J. Parotid gland basement membrane variation in diabetes Mellitus. J of Oral Pathol 1985: 14: 236-46(14)

[14]. Pamlona MC et al. Dental considerations in patients with heart disease. J clin Exp Dent 2011;3(2):e97-105(2).

[15]. Ackerman BH, Kasbekar N. Disturbances of taste and smell induced by drugs. Pharmacotherapy 1997;17:482-96.(23). 


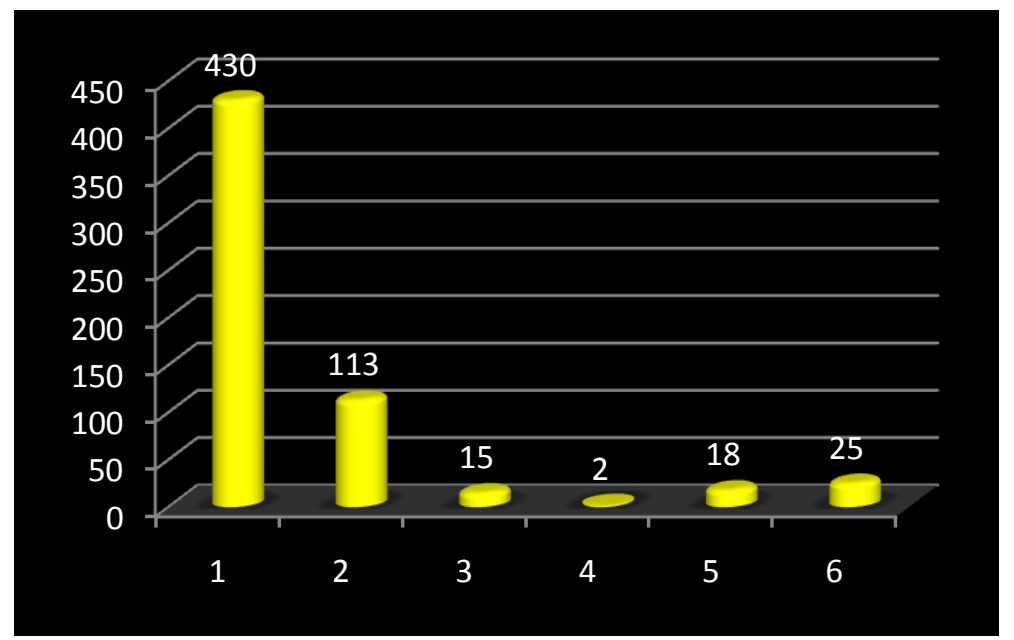

Fig.1 Disease frequency

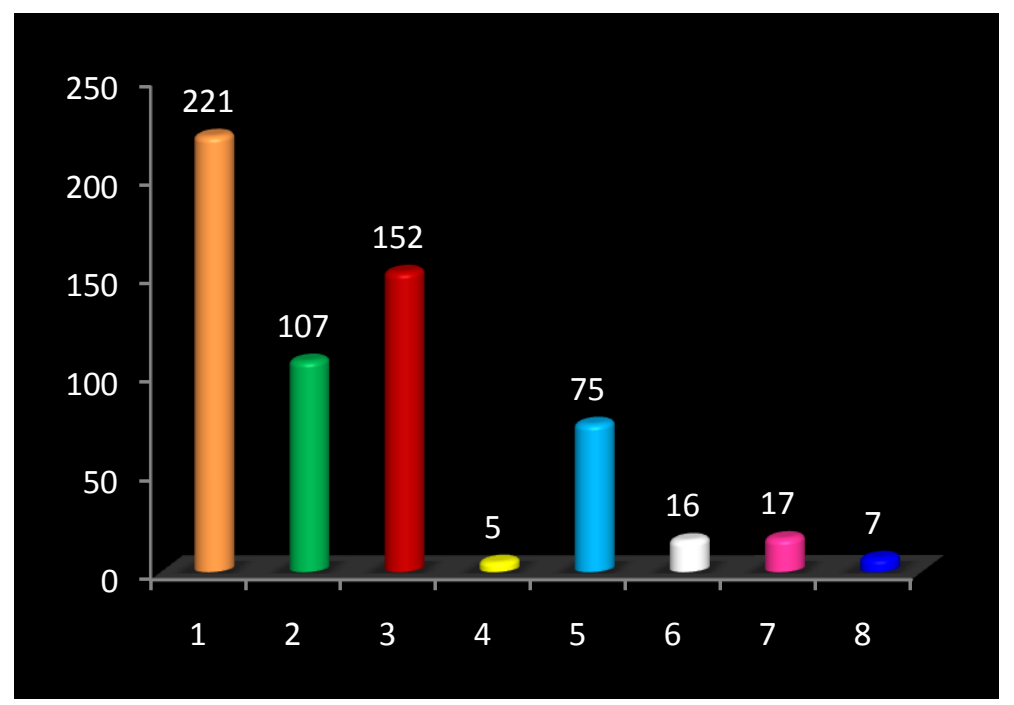

Fig.2 Frequency of Symptoms

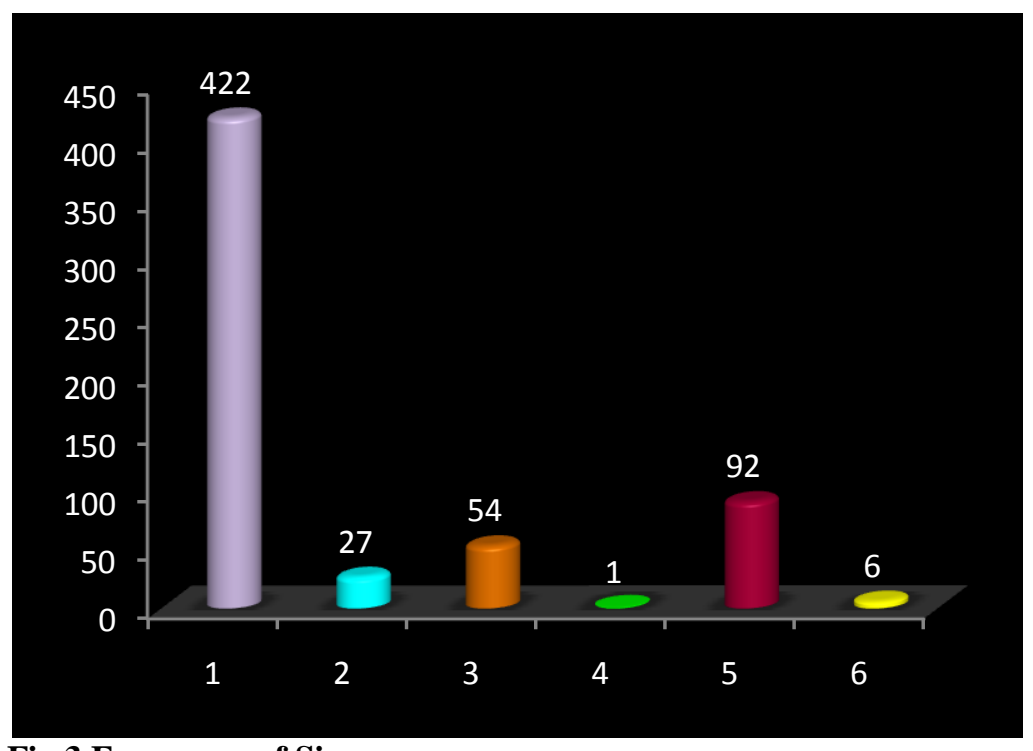

Fig.3 Frequency of Signs

\section{Cardiovascular Disease:}

1. Hypertension

2. Coronary heart diseases

3. Valvular heart diseases

4. Congenital heart diseases

5. Cardiac arrhythmias

\section{Oral symptoms:}

1. No symptoms

2. Dysgeusia

3. Xerostomia

4. Burning sensation(BS)

5. Xerostomia+ Dysgeusia

6. Dysgeusia + BS

7. Xerostomia + Dysgeusia + BS

8. Xerostomia $+\mathrm{BS}$

\section{Oral signs:}

1. No signs

2. Lichenoid reactions

3. Gingival enlargement

4. Aphthous ulcer

5. Xerostomia

6. Lichenoid + gingival enlargement 
Table1. Cardiovascular disease, risk factors, oral symptoms and signs in 603 patients:

\begin{tabular}{|c|c|c|}
\hline Variable & Frequency(No) & Percentage (\%) \\
\hline Males & 351 & 58.2 \\
\hline Females & 252 & 41.8 \\
\hline \multicolumn{3}{|l|}{ Risk factors: } \\
\hline No risk factors & 221 & 36.7 \\
\hline 1. Smoking & 55 & 9.1 \\
\hline 2.Diabetes mellitus & 53 & 8.8 \\
\hline 3.Smoking+DM & 10 & 1.5 \\
\hline \multicolumn{3}{|l|}{ Cardiovascular Disease: } \\
\hline 1.Hypertension & 430 & 71.3 \\
\hline 2.Coronary heart diseases & 113 & 18.7 \\
\hline 3.Valvular heart diseases & 15 & 2.8 \\
\hline 4.Cardiac arrhythmias & 18 & 3 \\
\hline 5.Congenital heart diseases & 2 & 0.3 \\
\hline 6.Congestive heart failure & 25 & 4.1 \\
\hline \multicolumn{3}{|l|}{ Cardiac drugs: } \\
\hline 1.Beta adrenergic blockers(BABs) & 24 & 4 \\
\hline 2.Calcium -channel blockers(CCBs) & 98 & 16.3 \\
\hline 3. $\mathrm{BABs}+\mathrm{CCBs}$ & 112 & 18.6 \\
\hline 4.BABs + Diuretics & 39 & 6.5 \\
\hline 5.BABs+ Angiotensin converting enzyme & 37 & 6.1 \\
\hline $\begin{array}{l}\text { inhibitor(ACEIs) } \\
\text { 6.BABs+ CCBs+ Anti-anxiety drugs }\end{array}$ & 31 & 5.1 \\
\hline 7.Cogestive heart failure (CHF) drugs & 44 & 7.3 \\
\hline \multicolumn{3}{|l|}{ (Digoxin+Duiretics+arteriole/venous/combined dilators) } \\
\hline 8.Penidure+antiplatelet & & \\
\hline 9.Coronary artery disease medications & 6 & 1 \\
\hline (Nitrates+Ca-ch/K channel openers/BAB+ Statins + & 103 & 17.1 \\
\hline \multicolumn{3}{|l|}{ Antiplatelets ) } \\
\hline \multicolumn{3}{|l|}{ 10.Penidure+ Any anti HTN drugs } \\
\hline 11.Congenital heart disease medication & 10 & 1.7 \\
\hline 12. Any CVD drugs +anti-diabetic drugs & 2 & 0.3 \\
\hline 13.CCBs + anti-anxiety drugs & 55 & 9.1 \\
\hline 14.CCBs +Diuretics & 14 & 2.3 \\
\hline 15.Coronary artery disease medication + antianxiety & 6 & 6 \\
\hline drugs & 5 & 0.8 \\
\hline \multicolumn{3}{|l|}{ 16.Anti HTN + Antiplatelets drugs } \\
\hline & 15 & 2.8 \\
\hline \multicolumn{3}{|l|}{ Oral symptoms: } \\
\hline Xerostomia & 152 & 25.5 \\
\hline Dysgeusia & 10 & 10 \\
\hline Burning sensation(BS) & 6 & 6 \\
\hline Xerostomia+ Dysgeusia & 75 & 12.4 \\
\hline Dysgeusia + BS & 18 & 3 \\
\hline Xerostomia +Dysgeusia+ BS & 1 & 2.8 \\
\hline Xerostomia + BS & 7 & 1.2 \\
\hline \multicolumn{3}{|l|}{ Oral signs: } \\
\hline Lichenoid reactions & 27 & 4.5 \\
\hline Gingival enlargement & 54 & 9 \\
\hline Xerostomia & 92 & 15.3 \\
\hline Xerostomia + gingival enlargement & 7 & 1.2 \\
\hline
\end{tabular}

Table.2. Co-relation of the oral manifestations with the number of medications

\begin{tabular}{|l|l|}
\hline No of patients with or without symptoms/signs & Mean no of medications \\
\hline Without symptoms(221) & $3.22+/-1.2$ \\
\hline With symptoms(382) & $3.4+/-2.0$ \\
\hline Without signs(422) & $2.49+/-0.91$ \\
\hline With signs(181) & $2.90+/-1.76$ \\
\hline
\end{tabular}


Table. 3 Cardiovascular drugs and oral symptoms and signs: CVS drugs symptoms - p<0.001(HS): CVS drugs signs- $\mathrm{p}=\mathbf{0 . 0 1}(\mathrm{S})$

\begin{tabular}{|c|c|c|c|c|c|c|c|c|c|c|c|c|c|}
\hline \multirow[b]{2}{*}{ Cardiovascular drugs } & \multicolumn{8}{|c|}{ Oral Symptoms } & \multicolumn{5}{|c|}{ Oral Signs } \\
\hline & $\begin{array}{l}\text { No } \\
\text { n-221 } \\
(36.790)\end{array}$ & $\begin{array}{l}\text { Dysgeusia } \\
\text { n-107 } \\
(17.940)\end{array}$ & $\begin{array}{l}\text { Xerostomi } \\
\mathrm{n}-152 \\
(25.5 \%)\end{array}$ & $\begin{array}{l}\text { Burning } \\
\text { Sensation } \\
n-6 \\
(640) \\
\end{array}$ & $\begin{array}{l}\text { Xero+dys } \\
\text { u- }-75 \\
(12.496)\end{array}$ & $\begin{array}{l}\text { Dys+BS } \\
\mathrm{n}-18 \\
(3 \%)\end{array}$ & $\begin{array}{l}\text { Xero+Dys } \\
+\mathrm{BS} \\
\mathrm{n}-1 \\
(2.890)\end{array}$ & $\begin{array}{l}\text { Xero+BS } \\
\mathrm{n}-7 \\
(1.296)\end{array}$ & $\begin{array}{l}\text { No } \\
\mathrm{n}-422 \\
(70 \%)\end{array}$ & $\begin{array}{l}\text { Liche } \\
\text { reaction } \\
\mathrm{n}-27 \\
(4.596) \\
\end{array}$ & $\begin{array}{l}\text { Gingival } \\
\text { enlaregentu } \\
n-54 \\
(940) \\
\end{array}$ & $\begin{array}{l}\text { Xerostomia } \\
\mathrm{n}-92 \\
(15.3 \%)\end{array}$ & $\begin{array}{l}\text { Lichenoi+ } \\
\text { Xerostomia } \\
\text { n-7 } \\
(1.290) \\
\end{array}$ \\
\hline B-adrenergic Blocker-24(496) & $9(4.5)$ & $3(2.8)$ & $10(6.6)$ & 0 & $2(2.7)$ & 0 & 0 & 0 & $18(43)$ & $1(3.7)$ & $2(3.7)$ & 3(3) & 0 \\
\hline Ca-ch blocker-98(16.39) & $44(199)$ & $14(13.1)$ & $29(19.1)$ & 0 & $7(93)$ & $2(125)$ & $1(59)$ & $1(143)$ & $67(159)$ & $2(7.4)$ & $18(333)$ & $10(109)$ & $1(16.7)$ \\
\hline BBB + Ca ch blocker-112(18.60.6) & $44(199)$ & $17(159)$ & $33(21.7)$ & 0 & $15(20)$ & $2(125)$ & 0 & $1(143)$ & $82(19.40$ & $5(185)$ & $15(27.8)$ & $9(9.8)$ & $1(16.7)$ \\
\hline BBB+Diuretics-39(6.59.6) & $11(5)$ & $4(3.7)$ & $14(9.2)$ & $1(20)$ & $7(9.3)$ & $1(6.3)$ & 0 & $1(143)$ & $25(5.5)$ & $4(14.8)$ & 0 & $10(10.9)$ & 0 \\
\hline $\mathrm{BBB}+\mathrm{ACEI}-37(6.1 \%)$ & $6(2.7)$ & $3(2.8)$ & $18(11.8)$ & 0 & $4(53)$ & $4(25)$ & $1(59)$ & $1(143)$ & $28(6.6)$ & $1(3.7)$ & 0 & $7(7.6)$ & 0 \\
\hline $\begin{array}{l}\text { BBB+Ca ch blocker+Anti anxity- } \\
31(5.19 .0)\end{array}$ & $12(5.4)$ & $9(8.4)$ & $4(2.6)$ & 0 & $4(53)$ & 0 & $2(11.8)$ & 0 & $28(6.6)$ & $1(3.7)$ & 0 & $1(1.1)$ & $1(16.7)$ \\
\hline $\begin{array}{l}\text { Digorin+Duiretics+arteriolé venousct } \\
\text { ombined dialators- } 44\left(734^{\circ}\right)\end{array}$ & $21(9.5)$ & $11(10.3)$ & $6(3.9)$ & 0 & $2(2.7)$ & 0 & $3(17.6)$ & $1(143)$ & $32(7.6)$ & 0 & $4(7.4)$ & $8(8.7)$ & 0 \\
\hline Peuidure+antiplatelet- $6(1 \%)$ & $3(1.4)$ & 0 & $1(0.7)$ & 0 & $2(2.7)$ & 0 & 0 & 0 & $5(1.2)$ & 0 & 0 & $1(1.1)$ & 0 \\
\hline $\begin{array}{l}\text { Nitrates }+\mathrm{Ca} \mathrm{a}-\mathrm{ch} / \mathrm{K} \text { channel } \\
\text { openers//Bblockers }+ \text { Statius + } \\
\text { Antiplatelets }-103(17.1 \%)\end{array}$ & $48(21.7)$ & $18(16.8)$ & $19(12.5)$ & $3(60)$ & $9(12)$ & 0 & $4(23.5)$ & $1(143)$ & $68(16.1)$ & $4(14.8)$ & $11(20.4)$ & $19(20.7)$ & $1(16.7)$ \\
\hline $\begin{array}{l}\text { Penidure+ Any antiHTN drugs- } \\
10(1.790)\end{array}$ & $2(0.9)$ & $5(4.7)$ & $3(2)$ & 0 & 0 & 0 & 0 & 0 & $6(1.4)$ & 0 & 0 & $4(43)$ & 0 \\
\hline Congenital HD drugs-2(0.3\%) & $1(0.8)$ & 0 & $1(0.8)$ & 0 & 0 & 0 & 0 & 0 & $2(0.5)$ & 0 & 0 & 0 & 0 \\
\hline $\begin{array}{l}\text { Auy CVS drug+Diabetic drug- } \\
55(9.196)\end{array}$ & $13(5.9)$ & $10(9.3)$ & $9(59)$ & $1(20)$ & $12(16)$ & $4(25)$ & $4(23.5)$ & 0 & $37(8.8)$ & $2(7.4)$ & $2(3.7)$ & $12(13)$ & $2(33.3)$ \\
\hline $\begin{array}{l}\text { Ca-ch drugs+antiauxiety drugs- } \\
14(2.3 \%)\end{array}$ & 0 & $2(1.9)$ & $3(2)$ & 0 & $6(8)$ & $1(6.3)$ & $1(5.9)$ & $1(143)$ & $5(1.2)$ & $5(18.5)$ & 0 & $3(33)$ & 0 \\
\hline Amlo+Diuretic- $6(19 \%)$ & 0 & $3(2.8)$ & 0 & 0 & $2(2.7)$ & $1(63)$ & 0 & 0 & $4(09)$ & $1(3.7)$ & $1(19)$ & 0 & 0 \\
\hline $\begin{array}{l}\text { Coronary medication+antianriety- } \\
\mathbf{5}(0.840)\end{array}$ & 0 & $4(3.7)$ & $1(0.7)$ & 0 & 0 & 0 & 0 & 0 & $2(0.5)$ & $1(3.7)$ & $1(19)$ & $1(1.1)$ & 0 \\
\hline Anti HTN + Antiplatęete-15(2.840) & $6(2.7)$ & $2(1.9)$ & $2(1.3)$ & 0 & $3(4)$ & $1(6.3)$ & $1(5.9)$ & 0 & $11(2.7)$ & 0 & 0 & $4(43)$ & 0 \\
\hline
\end{tabular}

